\title{
A preliminary analysis and discussion of the condominium building collapse in surfside, Florida, US, June 24, 2021
}

\author{
Xinzheng LU $^{\mathrm{a}}$, Hong GUAN ${ }^{\mathrm{b}}$, Hailin SUN ${ }^{\mathrm{c}}$, Yi LI ${ }^{\mathrm{d}}$, Zhe ZHENG ${ }^{\mathrm{a}}$, Yifan FEI ${ }^{\mathrm{a}}$, Zhi YANG ${ }^{\mathrm{b}, \mathrm{d}}$, Lingxiao ZUO \\ ${ }^{a}$ Key Laboratory of Civil Engineering Safety and Durability of Ministry of Education, Tsinghua University, Beijing 100084, China \\ ${ }^{b}$ School of Engineering and Built Environment, Griffith University Gold Coast Campus, Queensland 4222, Australia \\ ${ }^{c}$ China Architecture Design \& Research Group Co., Ltd, Beijing 100044, China \\ ${ }^{d}$ Beijing Key Laboratory of Earthquake Engineering and Structural Retrofit, Beijing University of Technology, Beijing 100124, \\ China \\ *Corresponding author.E-mail: luxz@tsinghua.edu.cn
}

(C) The Author(s) 2021. This article is published with open access at link.springer.com and journal.hep.com.cn

\begin{abstract}
On June 24, 2021, a 40-year-old reinforced concrete flat plate structure building in Miami suffered a sudden partial collapse. This study analyzed the overall performance and key components of the collapsed building based on the building design codes (ACI-318 and GB 50010). Punching shear and post-punching performances of typical slabcolumn joints are also studied through the refined finite element analysis. The collapse process was simulated and visualized using a physics engine. By way of these analyses, weak design points of the collapsed building are highlighted. The differences between the reinforcement detailing of the collapsed building and the requirements of the current Chinese code are discussed, together with a comparison of the punching shear and post-punching performances. The simulated collapse procedure and debris distribution are compared with the actual collapse scenes.
\end{abstract}

KEYWORDS progressive collapse, flat plate, simulation, punching

\section{Background}

On June 24, 2021, at approximately 1:30 a.m. EDT (Eastern Daylight Time), Champlain Towers South Condominium, a 12/13-story 40-year-old reinforced concrete (RC) flat plate structure building in the Miami suburb of Surfside, Florida, United States, experienced a sudden partial collapse. As of July 22, 2021, 98 people had been confirmed dead [1].

In the last few decades, progressive collapse of RC flat plate structures has occurred worldwide, causing substantial loss of life and property. A progressive collapse initiates as a result of local structural damage and develops, by way of a chain reaction mechanism, into a failure that is disproportionate to the initiating local damage [2]. Flat plate structures are vulnerable to punching shear failure induced by accidental or abnormal

Article history: Received Jul 4, 2021; Accepted Jul 29, 2021 loading (e.g., gas explosion, fire, blast, vehicular collision, and natural disasters), which may trigger this catastrophic disproportionate collapse of the entire structure. Collapses of the Boston federal avenue apartment in 1971, the Sampoong department store in 1995, and the Swiss Solothurn garage in 2004 are typical progressive collapse events of concrete flat plate systems [3-5].

Currently, the underlying causes of the collapse of the Champlain Towers South Condominium are still unknown. Some researchers believe that this sudden catastrophic incident was due to multi-damage and multifailure mechanisms. Likely causes including differential settlement of the foundation, corrosion of the reinforcement and cracking of the concrete, and the longterm waterproofing problem, have been identified in an early evaluation of this building [1]. These factors could have led to the progressive degradation of the building, 
and they could all play a key role in its partial collapse. However, no indicative and inclusive conclusions have been reached on the initiation of the collapse. Based on the site investigation, many researchers have pointed out that punching shear failure at the slab-column joints might be one of the most likely reasons [6].

Existing design codes specify clear requirements on the punching shear strengths of slab-column joints, as well as the axial strengths of columns $[7,8]$. Due to significant uncertainty in estimating the punching shear strength, most design codes only consider the contribution of concrete to the punching shear strength. The contribution of reinforcement is taken as a safety margin. The progressive collapses of flat-plate structures are likely induced by the brittle punching shear failure or the failure of one or more columns. Therefore, a strength check on the joints and columns of the collapsed building should be the first step for a forensic investigation, which is introduced in Section 2 of this paper.

The structural system also plays an important role in the collapse-prevention of the building. Figure 1 clearly shows that the middle and eastern parts of the building collapsed, whereas the west part of the building survived. From the surveillance video recording of the collapsing building, the collapse initiated from the middle part of the building and propagated to the east side. Consequently, a study on the entire structural system is also needed to understand the vertical and horizontal load resisting mechanisms of the building. Note that modern structural design software also provides a very convenient designcode-check function. The design aspects that cannot satisfy the code requirement can be clearly observed from the structural models in the design software. Consequently, a structural model of the collapsed building is also established and analyzed in Section 2 of this paper.

As mentioned above, the mechanical behaviors of the slab-column joints are critical to the integrity of the collapsed building. Given that many factors (e.g., the contribution of reinforcement) are considered as the safety margin and neglected by the current design code in

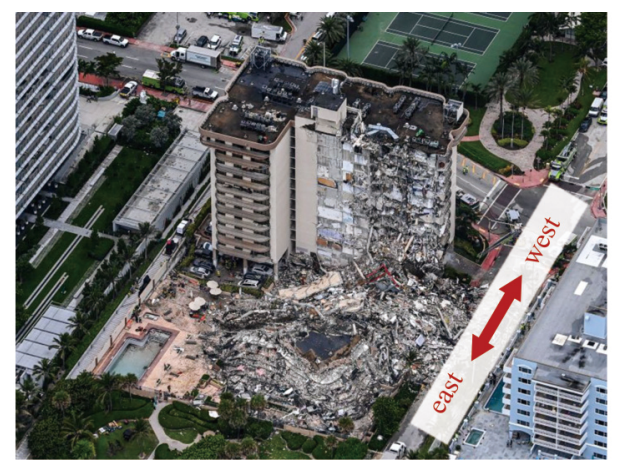

Fig. 1 Collapsed Champlain Towers South Condominium (photo via Agence France-Presse). the strength calculation of the joints, a refined finite element (FE) analysis of a representative joint is necessary to provide an insightful understanding of its failure mechanism. Furthermore, as the progressive collapse of a structure is induced by accidental loading, it is rather difficult to predict the potential collapse during the design stage of the structure. Therefore, most progressive collapse prevention strategies are established to ensure that the structure has sufficient load redistribution capacity after the initial localized failure occurs. Such a strategy requires that the structure should have sufficient collapse resistance at the large deformation stage, during which the reinforcement detailing plays a critical role in ensuring the strength and deformation capacities of the slab-column joints. Note that different design codes set distinctively different requirements for the reinforcement detailing of the joints $[7,8]$. The performance difference of various kinds of detailing can only be compared through experiments or refined FE analyses [9-16]. Experimentally, the punching shear and post-punching failure behaviors of a series of interior slab-column joints subjected to either concentric loading or eccentric loading were investigated, considering the effects of different punching shear directions, slab thicknesses, reinforcement ratios, and strengthening methods $[10,14,15]$. It was found that the post-punching bearing and deformation capacities of the slab-column joints were predominantly determined by the through-column integrity reinforcement, and the addition of the embedded beams facilitated greater deformation and load capacities in the large-deformation suspension stage. Xue et al. [9] and Ma et al. [12,13] conducted a series of tests of flat plate substructures subjected to either concentrated load on the column stub or uniformly distributed load on the slab. The load redistribution patterns of these substructures were examined and accurately quantified under different column removal scenarios. Numerically, a set of 3D nonlinear finite element modeling techniques, using LS-DYNA software, was proposed to investigate the progressive collapse behavior of flat plate structures $[10,14,15]$. For computational efficiency, an FE analysis of a representative slab-column joint of the collapsed building is performed and detailed in Section 3 of this paper. Section 3 also presents a comparison of the representative joint to the joint designed following the reinforcement detailing specified in the Chinese code.

In addition to the above-mentioned experimental and numerical studies conducted at the joint and substructure levels, the collapse simulation of the overall structure also plays a key role in better understanding the progressive collapse behavior of the overall structural system. Existing studies have mainly used two types of methods for collapse and debris scenario simulations, i.e., experiments or numerical simulations. Due to the high cost of experiments and limited experimental capacity, small-scale specimens are often tested, which affects the 
reliability of the experimental outcomes. The commonly used numerical simulation methods for structural collapse process and debris distribution simulation include the FE method, DEM (Discrete element method) [17,18], AEM (Applied element method) [19,20], and physics engines. Remarkably, the FE method has been used in many existing studies to simulate the collapse behavior of buildings. For instance, a number of FE method-based studies have focused on the collapse resistance of structures before the formation of debris [21-28]. In contrast, studies on the collapse debris distribution are relatively limited, mainly due to the high computational cost of the FE simulations for such problems [20,29]. A physics engine is a computer graphics technology specializing in calculating the complex physical behaviors of objects, such as the spread of smoke, the flow of water, and rigid body collisions [30]. In recent years, it has been widely used in the simulations of structural collapse processes and debris distributions [31-35]. Some researchers have also combined multiple numerical simulation methods for collapse simulation. Zheng et al. [36] proposed a framework for simulating building collapse and debris scenarios by combining FE analysis and a physics engine approach. Due to the effective integration of the advantages of the two methods, the framework was able to accurately simulate the entire process from building collapse to debris formation. For this reason, this framework is adopted herein and modified accordingly to simulate the collapse procedure of the collapsed building, which is introduced in Section 4 of this paper.

The progressive collapse of the Champlain Towers South Condominium is likely to have been caused by a combination of different factors. In this work, to explore the collapse mechanism of this 40-year-old flat plate structure, both analytical and numerical investigations are conducted based on our research outcomes acquired to date, which cover the following three major aspects. 1) Design requirement. Given that this is an old building, the design requirements it followed may not necessarily meet current design standards. Nevertheless, evaluation of the current design requirements can still help to reveal the potential weak portions of the structural system. 2) Mechanical behaviors of slab-column joints. Punching shear failure of slab-column joints in a flat plate system is regarded as the most plausible cause of initial local damage that may propagate throughout the entire structure. In addition, the post-punching resistant capacity also plays a vital role in resisting progressive collapse. 3) Simulation of the entire collapse process. Accurately simulating the collapse process is crucial to understanding the possible collapse progression and the failure mechanisms of the structure. Note that the modern-day Chinese code is used in the preliminary analysis because it is one of the state-of-the-art building design codes which can provide a relatively comprehensive evaluation of structural safety. The use of this code has also facilitated a preliminary analysis to be undertaken in a timely manner soon after the collapse event.

We acknowledge that this work is a preliminary study. The analyses and conclusions of this work are based on the available information with certain assumptions and simplifications. As such, the study outcomes are not anticipated to be used directly for forensic analyses or any other technical purposes. The intended purpose of this work is to provide a reference base for the forthcoming detailed forensic analyses and discussions of the cause of the failure of the Miami condominium building. We also hope to offer an analysis framework for assessing the structural adequacy of similar structures. It is worth noting that this work focuses on the design of the collapsed building only. Hence, our conclusions are only applicable to this specific building as well.

\section{Structural system analysis}

\subsection{The structural system}

The computational model is established based on the design drawings of the collapsed building provided in Ref. [37]. Material strengths and geometric dimensions as specified in the design drawings are adopted in our analysis. The story height and the concrete strengths of the building are given in Table 1 . The typical story height is 8 feet and 10 inches (approximately $2.69 \mathrm{~m}$ ). Note that this building was designed and constructed in 1981, and the design requirements in the 1980s are inevitably different from the current ones. To facilitate useful discussions on the design requirements, the current Chinese and American Concrete Institute (ACI) codes $[7,8]$ on punching shear strength predictions are compared. Also note that due to the lack of detailed information, conceivable degradation in structural capacity caused by the accumulated damage (differential settlement of the foundation, corrosion of the reinforcement and cracking of the concrete, etc.) are not considered in this study.

The typical planar layout of a standard story is shown in Fig. 2. The slab thickness of the standard story and roof story is 8 inches (approximately $203 \mathrm{~mm}$ ), while that of the ground story is 9 and 9.5 inches (approximately 229 and $241 \mathrm{~mm}$ ).

\subsection{Punching strength check for a typical slab-column joint}

The flat plate slab-column joint located at the intersection of the L-axis and 8-axis (Fig. 2) is selected as a typical joint in the study. The following material and geometric properties are considered. The specified 28-d cylinder compressive strength of the concrete is $20.68 \mathrm{MPa}$. The 
Table 1 Typical structural height and concrete strengths

\begin{tabular}{lcccc}
\hline story number & $\begin{array}{c}\text { elevation } \\
H(\mathrm{~m})\end{array}$ & $\begin{array}{c}\text { story } \\
\text { height (m) }\end{array}$ & $\begin{array}{c}\text { concrete strength } \\
\text { of the slab } \\
(\mathrm{MPa})\end{array}$ & $\begin{array}{c}\text { concrete strength } \\
\text { of wall and } \\
\text { column (MPa) }\end{array}$ \\
\hline basement & - & - & 27.58 & 41.37 \\
-1 & -3.378 & 3.378 & 27.58 & 41.37 \\
1 & \pm 0.000 & 4.166 & 27.58 & 41.37 \\
2 & 4.166 & 2.693 & 27.58 & 41.37 \\
3 & 6.859 & 2.693 & 27.58 & 41.37 \\
4 & 9.552 & 2.693 & 27.58 & 34.47 \\
5 & 12.245 & 2.693 & 27.58 & 34.47 \\
6 & 14.938 & 2.693 & 27.58 & 34.47 \\
7 & 17.631 & 2.693 & 27.58 & 34.47 \\
8 & 20.324 & 2.693 & 27.58 & 27.58 \\
9 & 23.017 & 2.693 & 20.68 & 27.58 \\
10 & 25.710 & 2.693 & 20.68 & 27.58 \\
11 & 28.403 & 2.693 & 20.68 & 27.58 \\
12 & 31.096 & 2.693 & 20.68 & 27.58 \\
roof & 33.789 & 2.693 & 20.68 & 27.58 \\
elevator roof & 38.463 & 4.674 & 20.68 & 27.58 \\
\hline & & & & \\
\hline
\end{tabular}

slab thickness is 8 inches $(203.2 \mathrm{~mm})$. The reinforcement at the bottom of the slab is \#4 $(0.5$ inches or $12.7 \mathrm{~mm})$. The dimension of the column is 14 inches $\times 18$ inches (355.6 $\mathrm{mm} \times 457.2 \mathrm{~mm})$. A 3/4-inch $(19.05 \mathrm{~mm})$ cover layer is assumed for the column.

The collapsed building is a condominium. Currently, no clear information of the dead and live loads of the building is available. Consequently, several different scenarios are considered herein to ensure the rationality of the computed punching strength results. Four dead load scenarios (i.e., the dead load in addition to the slab self-weight and the dead load of the walls) are considered. Note that the different load combinations are also set to meet the requirements of different design codes. The code-specified punching loads (demands) and the corresponding punching shear resistances (capacities) of the joint are summarized in Table 2.

Table 2 clearly shows that when the concrete strength is $20.68 \mathrm{MPa}$, the demand-capacity ratios of the joint following ACI-318 [7] cannot meet the requirement for most load scenarios. Note that the Chinese code [8] predicts a smaller punching shear resistance than ACI318 [7]. Consequently, the joint also cannot satisfy the

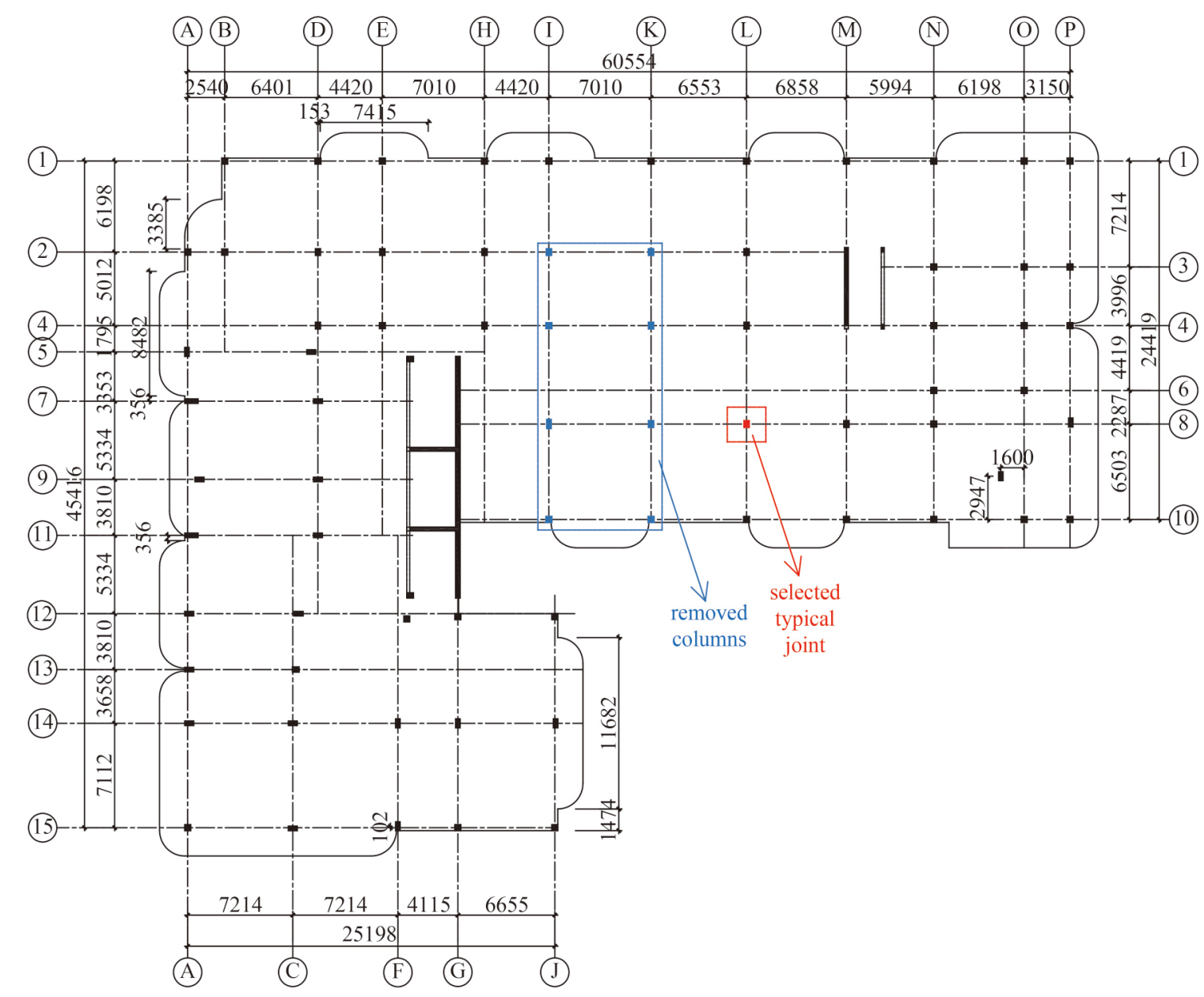

Fig. 2 Planar layout of a standard story (unit: $\mathrm{mm}$ ). 
Table 2 Punching resistance checking of a slab-column joint L-8

\begin{tabular}{|c|c|c|c|c|c|c|c|c|c|}
\hline \multirow{2}{*}{$\begin{array}{l}\text { concrete } \\
\text { strength } \\
\text { (MPa) }\end{array}$} & \multirow{2}{*}{$\begin{array}{c}\text { dead load in addition } \\
\text { to slab self-weight } \\
\left(\mathrm{kN} / \mathrm{m}^{2}\right)\end{array}$} & \multirow{2}{*}{$\begin{array}{l}\text { dead load of } \\
\text { walls }\left(\mathrm{kN} / \mathrm{m}^{2}\right)\end{array}$} & \multirow{2}{*}{$\begin{array}{l}\text { live load } \\
\left(\mathrm{kN} / \mathrm{m}^{2}\right)\end{array}$} & \multicolumn{4}{|c|}{ punching load (kN) } & \multicolumn{2}{|c|}{ punching resistance $(\mathrm{kN})$} \\
\hline & & & & $1.2 \mathrm{D}+1.6 \mathrm{~L}$ & $1.3 \mathrm{D}+1.7 \mathrm{~L}$ & $1.3 \mathrm{D}+1.5 \mathrm{~L}$ & $1.0 \mathrm{D}+1.0 \mathrm{~L}$ & ACI-318 [7] & GB 50010 [8] \\
\hline \multirow[t]{4}{*}{27.58} & 1.0 & 1.5 & 2 & 534.1 & 575.7 & 558.0 & 421.6 & 449.5 & 357.9 \\
\hline & 0.5 & 1.0 & & 480.9 & 518.1 & 500.3 & 376.7 & & \\
\hline & 0.3 & 0.5 & & 443.7 & 477.7 & 460.0 & 345.2 & & \\
\hline & 0.0 & 0.0 & & 405.6 & 436.4 & 418.5 & 309.2 & & \\
\hline \multirow[t]{4}{*}{20.68} & 1.0 & 1.5 & 2 & 540.0 & 582.0 & 564.1 & 421.6 & 519.0 & 429.0 \\
\hline & 0.5 & 1.0 & & 486.2 & 523.8 & 505.8 & 376.7 & & \\
\hline & 0.3 & 0.5 & & 448.6 & 483.0 & 465.1 & 345.2 & & \\
\hline & 0.0 & 0.0 & & 405.6 & 436.4 & 418.5 & 309.2 & & \\
\hline
\end{tabular}

Notes: D: dead load; L: live load.

Chinese code [8]. Even when the concrete strength is increased to $27.58 \mathrm{MPa}$, there are still some load scenarios that cannot meet the design requirement of the Chinese code [8], as seen in Table 2.

\subsection{Axial strength check for a typical column}

The columns located at the intersection of the L-axis and 8 -axis are selected as typical columns. Note that there are altogether 13 L-8 columns from the basement story to the roof story. For simplicity, for each concrete grade (i.e., $27.58,34.47,41.37 \mathrm{MPa}$ ), the column section with the maximum axial load is selected for the strength check. The axial contribution of the column reinforcement and the stability reduction are not considered. The calculated axial strength results are given in Table 3 . It clearly shows that the demand-capacity ratios of the axial strength are greater than 1.0, which means that the possibility of the column not satisfying the design requirement is significant.

\subsection{Analysis of the whole structure}

For the whole structure, the dead load in addition to the slab self-weight and the dead load of the walls are taken as 0.5 and $1.0 \mathrm{kN} / \mathrm{m}^{2}$, respectively. Considering high winds in the Miami Surfside region, a $1.1 \mathrm{kN} / \mathrm{m}^{2}$ equivalent wind load and a Roughness Site A specified in the Chinese code are adopted. Two numerical models of the collapsed building are established, corresponding to the scenarios of 6-degree seismic design intensity (the peak ground acceleration (PGA) is $50 \mathrm{~cm} / \mathrm{s}^{2}$ for $10 \%$ probability of exceedance in 50 years) and no seismic design requirement. The structural model is shown in Fig. 3.

The numerical results show that the axial compressive force ratios of many columns within the collapsed zone cannot satisfy the design requirement of the Chinese code [8] (shown by the red numbers in Fig. 4). Most of these columns have an axial force ratio greater than 1.6. The inter-story drift ratios subjected to the design wind load also exceed the 1/800 threshold specified in the Chinese code [8] (Figs. 5 and 6).

\subsection{Preliminary discussion on the collapse sequence}

According to the design practice of similar buildings in the United States, the columns usually only carry gravity loads. Lateral forces due to wind and earthquake are commonly resisted by shear walls. However, in the collapsed building, most of the shear walls are along the $Y$-axis (Fig. 7). In contrast, there are few shear walls along the $X$-axis (Fig. 7).

From the failure mode of the building (Fig. 7), it can be observed that after the collapse of the middle part of the building (the area with number 1 in Fig. 7), further propagation of the collapse to the west side was prevented by the shear wall along the G-axis (Fig. 7), because this shear wall and its flanges are sufficient long to resist lateral loads. In contrast, the shear wall along the M-axis is much shorter and has no flange (Fig. 7).

Table 3 Axial strength checking of column L-8

\begin{tabular}{lccccc}
\hline concrete strength (MPa) & $\begin{array}{c}\text { design axial strength } \\
\text { in Chinese code (MPa) }\end{array}$ & \multicolumn{3}{c}{ demand-capacity ratio } \\
\cline { 3 - 5 } & & Chinese code [8] & $1.2 \mathrm{D}+1.6 \mathrm{~L}$ & $1.3 \mathrm{D}+1.7 \mathrm{~L}$ & $1.0 \mathrm{D}+1.0 \mathrm{~L}$ \\
\hline 27.58 & 16.45 & 1.14 & 1.00 & 1.07 & 0.50 \\
34.47 & 20.34 & 1.55 & 1.34 & 1.42 & 1.66 \\
41.37 & 23.85 & 1.84 & 1.56 & 0.67 \\
\hline
\end{tabular}

Notes: D: dead load; L: live load. 
Consequently, its ability to resist the propagation of the collapse to the east side is very small so the eastern part of the building (the area with number 2 in Fig. 7) collapsed subsequently.

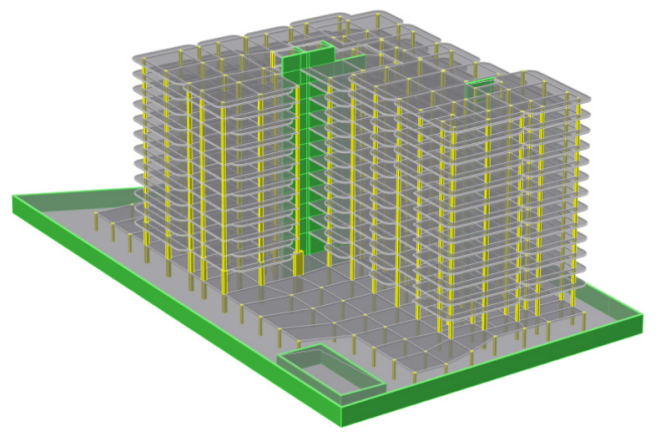

Fig. 3 Preliminary structural analysis model.
Furthermore, from the site investigation, it can be found that the shear walls surrounding the swimming pool effectively discontinued the propagation of the collapse in the basement, as shown in Fig. 8.

\section{Finite element analysis of a typical slab- column joint}

3.1 Construction detailing of slab reinforcement in the joint area

There are significant differences between the design philosophies for historic flat plate structures and those for modern ones, especially in terms of detailing requirements of the slab reinforcement. The collapsed structure was designed to the ACI-318 code prior to 1981 . The reinforcement layout of the column strip is shown in

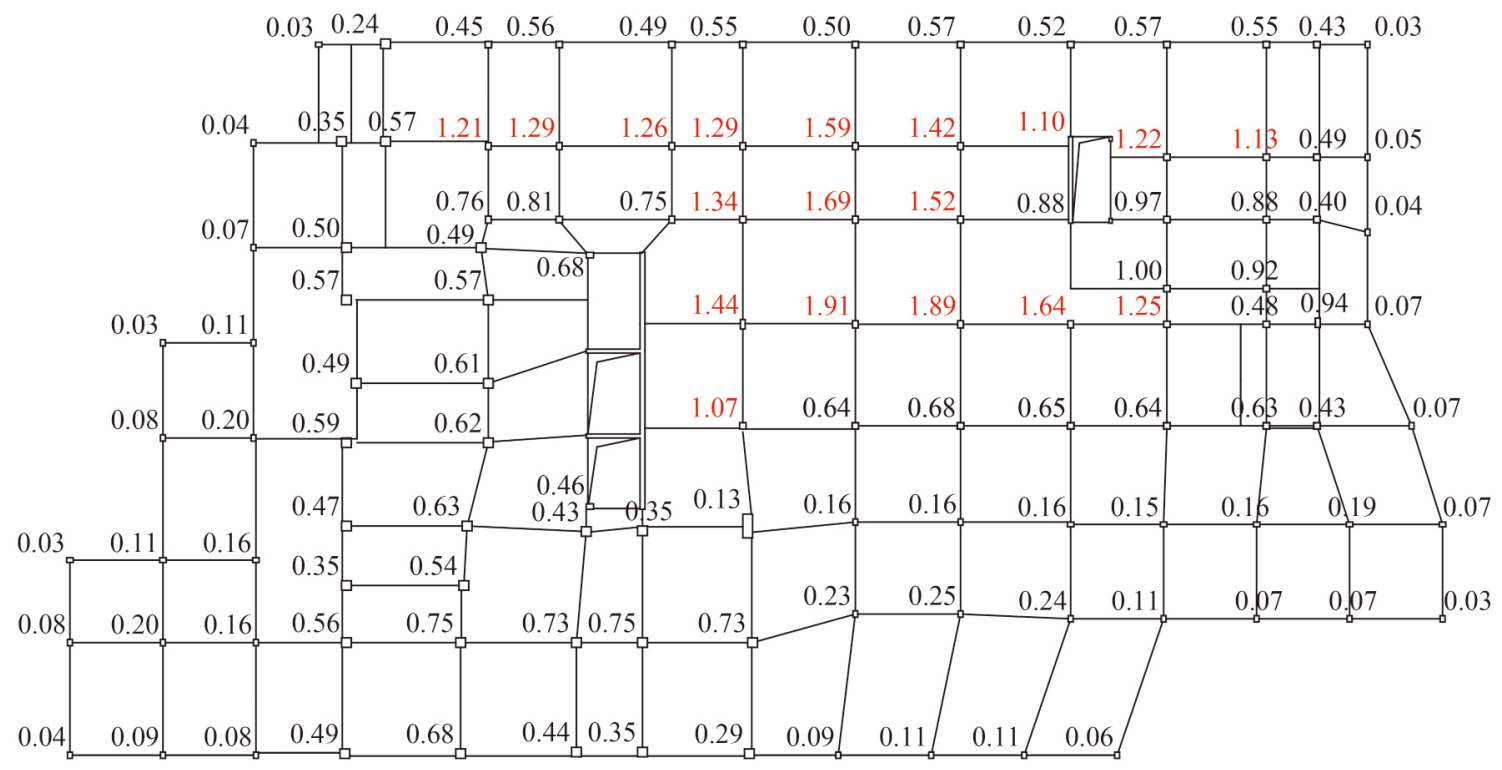

Fig. 4 Axial compressive force ratio of the columns on the basement story.

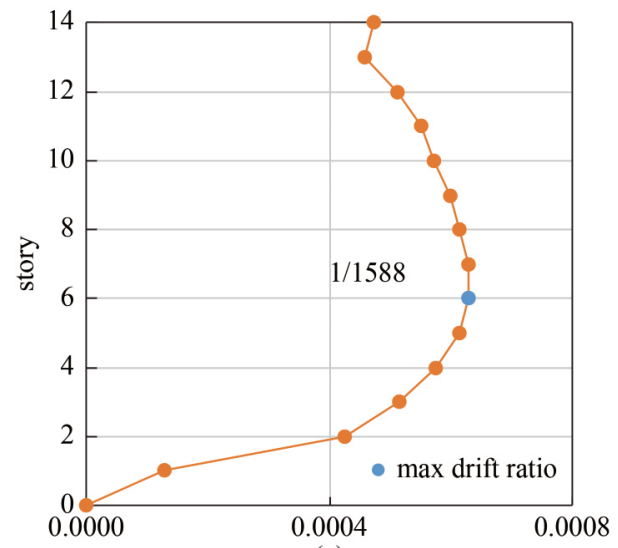

(a)

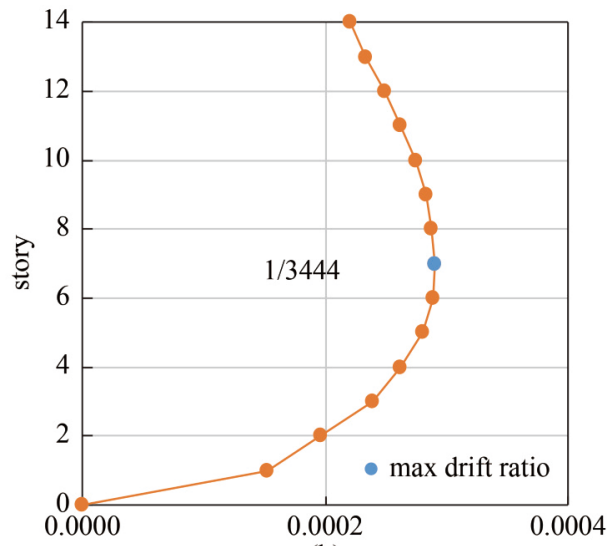

(b)

Fig. 5 Inter-story drift ratios subjected to service level earthquake (63\% probability of exceedance in 50 years). (a) Story drift ratio in $X$ direction (rad); (b) story drift ratio in $Y$ direction (rad). 


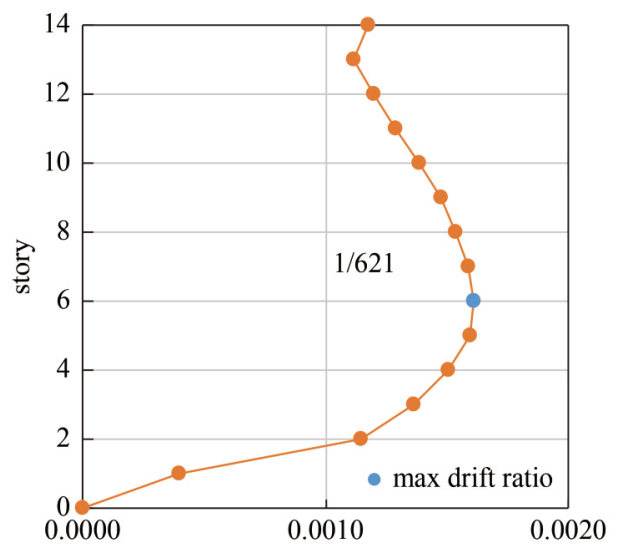

(a)

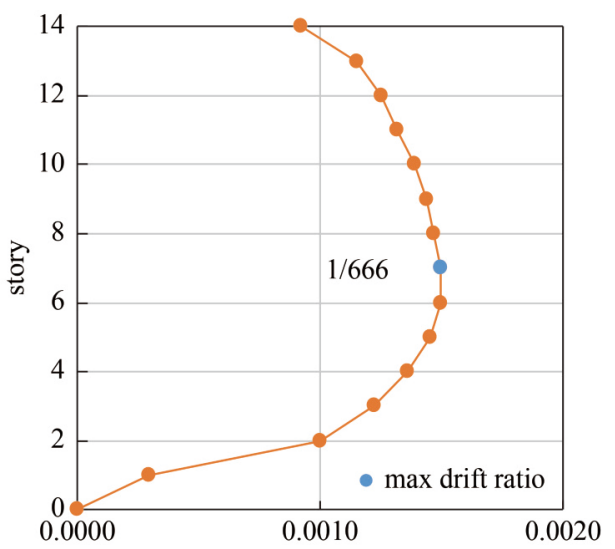

(b)

Fig. 6 Inter-story drift ratios subjected to design wind load. (a) Story drift ratio in $X$ direction (rad); (b) story drift ratio in $Y$ direction (rad).

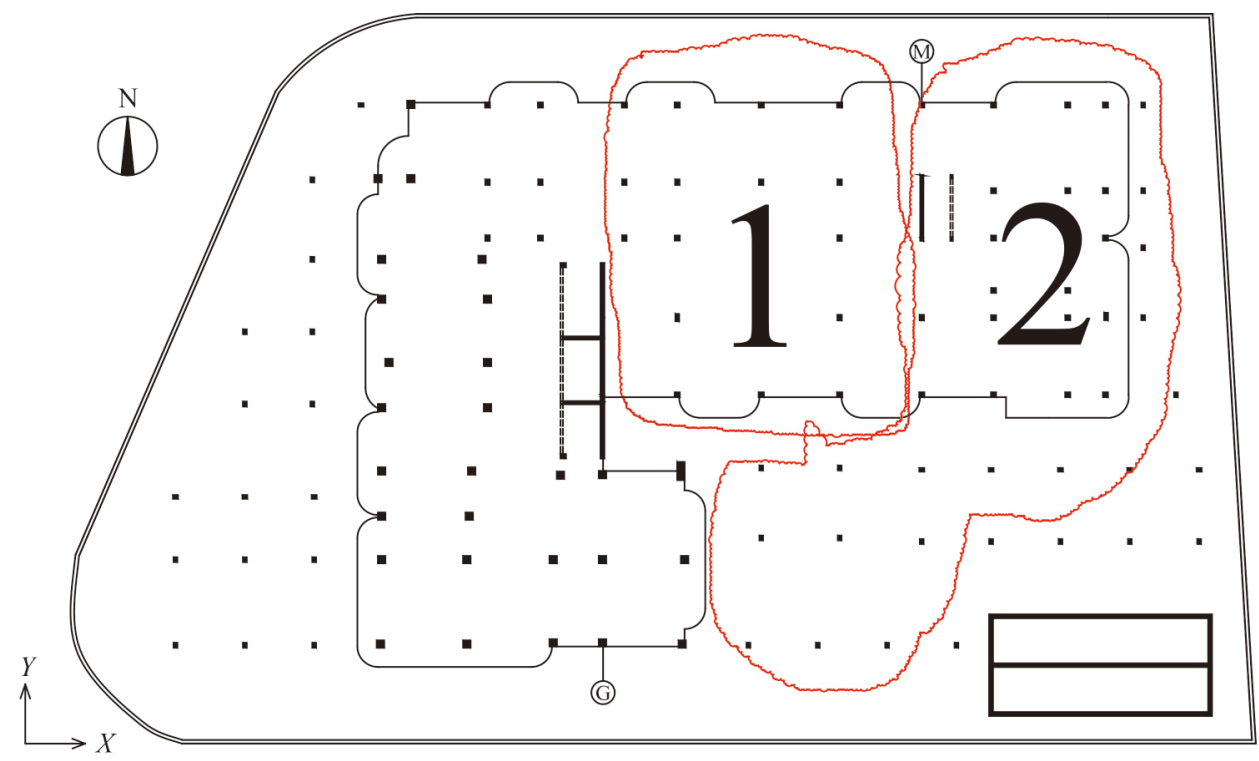

Fig. 7 The collapse sequence and the structural wall (shaded areas).
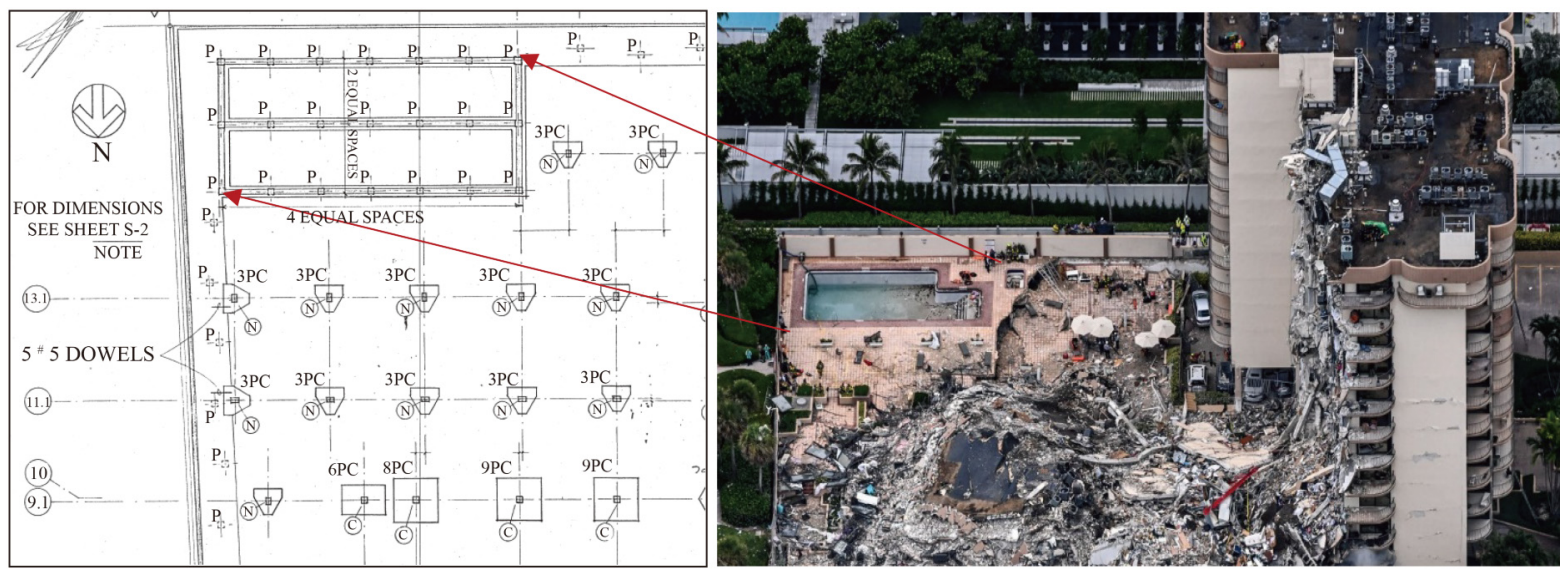

Fig. 8 Part of the shear wall of the swimming pool in the basement at the south-east corner (The design drawing be found in Ref. [37]. Photo via Agence France-Presse). 
Fig. 9. Previous studies [9-15] reveal that the mechanical performance of the slab-column joint after punching shear failure is mainly dominated by the through-column integrity rebars. The following two typical characteristics can be summarized from the reinforcement layout of the collapsed structure: 1) the flexural reinforcement at the slab top is trimmed at a certain distance away from the column faces; 2) half amount of the integrity reinforcement at the slab bottom is cut off at the slabcolumn joint region, and the remaining half is overlapped within the column region, in which the overlap length of the rebars is only $149 \mathrm{~mm}$. Such a reinforcement detailing is clearly insufficient to provide progressive collapse resistance at the large deformation stage. Therefore, since 1989, the ACI-318 code has incorporated structural integrity requirements that no less than two integrity (bottom) rebars must pass through the slab-column joint.

Compared to ACI-318 [7], the current Chinese Code for Design of Concrete Structures [8] has stricter requirements for structural reinforcement within slabcolumn joints. The reinforcement ratio of the flexural rebars at the slab top is required to be no less than $0.1 \%$ in each planar direction. Meanwhile, the continuous integrity reinforcement at the slab bottom is not allowed to be cut off. In addition, no more than $50 \%$ of reinforcement can be connected by overlapping, welding, or socketing at the same cross-section, etc. In accordance with the Chinese code [8], the overlap length should be $530 \mathrm{~mm}$ for the collapsed structure, which is much larger than the actual length of $149 \mathrm{~mm}$. Furthermore, the Chinese code also recommends using embedded beams for flat plate structures, requiring: 1) at least $1 / 2$ of the flexural reinforcement in the column strip should be restrained by the stirrups within the embedded beam; 2) the integrity reinforcement in the slab bottom should be restrained in the embedded beam should be no less than $1 / 2$ of the flexural reinforcement within the embedded beam. This detailing requirement significantly increases the number of through-column reinforcements. Previous studies $[14,15]$ confirm that the stirrups of the embedded beam can effectively restrain the non-through-column reinforcement in the vicinity of a slab-column joint, thereby increasing the post-punching resistance of the joint.

\subsection{Numerical investigations}

To better understand the behaviors of the interior slabcolumn joints of the collapsed building, a numerical investigation is conducted using LS-DYNA [38] based on the previously developed modeling approaches $[11,14,15]$. A 3D slab-column joint model with a halfspan slab (referred to as J1) is built first to examine the punching shear and post-punching failure behavior of the joint. On the basis of $\mathrm{J} 1$, another joint model, referred to as $\mathrm{J} 2$, is established incorporating the reinforcement detailing as per the current Chinese code [8]. The structural performances of $\mathrm{J} 1$ and $\mathrm{J} 2$ are further analyzed to compare the effects of different detailing requirements of different design codes on both punching and postpunching failure mechanisms. It should be noted that likely reduction of structural capacity due to accumulated damage (differential settlement, reinforcement corrosion, concrete cracking, etc.) is not considered in this study due to the lack of detailed information.

\subsubsection{Numerical models}

The numerical model $\mathrm{J} 1$ is built in accordance with the full-scale half-span interior slab-column joint extracted from the standard story (9th story) of the collapsed structure. The modeling area is enveloped by the redcolored square shown in Fig. 2. To facilitate effective mesh subdivision, the actual dimensions are rounded to the nearest tens, as detailed in Table 4. Note that the material properties, geometric dimensions, and reinforcement layout of $\mathrm{J} 1$ are kept consistent with those of the collapsed structure. Based on the $\mathrm{J} 1$ model, the $\mathrm{J} 2$ model is built with the same concrete elements but different detailing reinforcement as per the Chinese code [8].

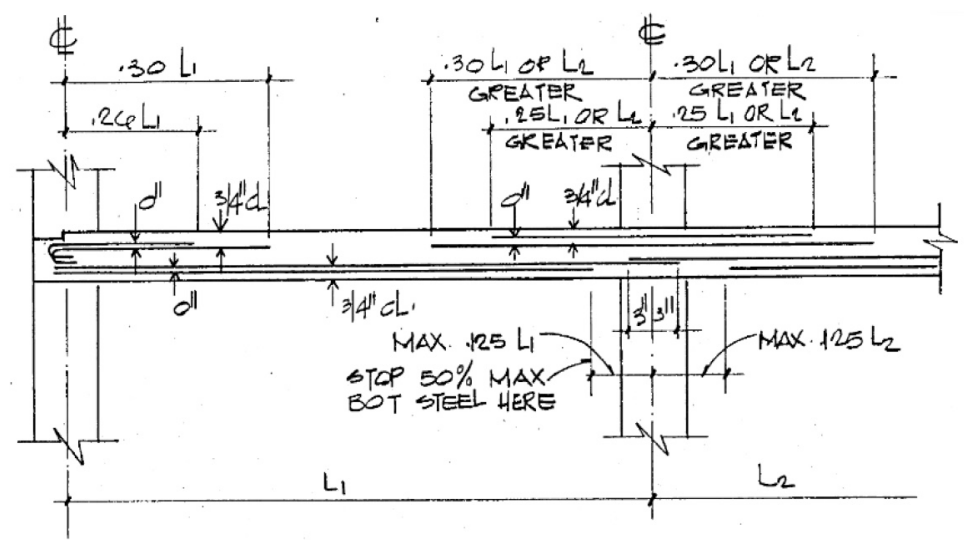

Fig. 9 Reinforcement layout of the column strip [37]. 
Table 4 Dimensions of the collapsed structure and the numerical model

\begin{tabular}{lcccc}
\hline type & span length $(\mathrm{mm})$ & concrete cover $(\mathrm{mm})$ & column $(\mathrm{mm})$ & slab thickness $(\mathrm{mm})$ \\
\hline collapsed structure & 6660 & 19 & $356 \times 457$ & 203 \\
numerical model & & & $360 \times 460$ & 200 \\
\hline
\end{tabular}

\subsubsection{Geometric and elemental models}

Figures 10 and 11 present the FE model of the $\mathrm{J} 1$, and the reinforcement layout of the $\mathrm{J} 1$ and $\mathrm{J} 2$ models, respectively. Concrete is modeled using eight-node 3D solid elements. Reinforcing bars are explicitly modeled by two-node Hughes-Liu beam elements with a $2 \times 2$ Gauss quadrature integration scheme. To reproduce the physical contact between the orthogonal layers of reinforcement at the slab top and bottom, the keyword *CONTACT_AUTOMATIC_GENERAL is used. To balance solution accuracy and computational efficiency, a combination of mixed concrete element dimensions of 27.5, 28.75, and $30 \mathrm{~mm}$ are used. For the slab reinforcement, an element length of $30 \mathrm{~mm}$ is chosen.

\subsubsection{Material properties}

A continuous surface cap model (CSCM) (*MAT_159) is used to simulate the concrete material behavior. In addition, the erosion function is adopted to simulate concrete spalling and separation and to eliminate excessively distorted elements. An isotropic elasticplastic material model *Mat_Piecewise_Linear_Plasticity is used for reinforcing bars. Interactions between the rebar beam elements and the concrete solid elements are simulated using the keyword *CONSTRAINED_BEAM_ IN_SOLID.

\subsubsection{Boundary conditions}

Simple supports are applied to the slab edge surface. To simulate the slab in-plane restraints of the isolated $\mathrm{J} 1$ and J2 models supposedly provided by the surrounding slabs and columns in a continuous flat plate structure, spring elements are utilized to provide horizontal restraints to the slab boundaries. A spring stiffness of $1200 \mathrm{~N} / \mathrm{mm}$ is set [16]. The rationality of such boundary conditions can be found in Ref. [16].

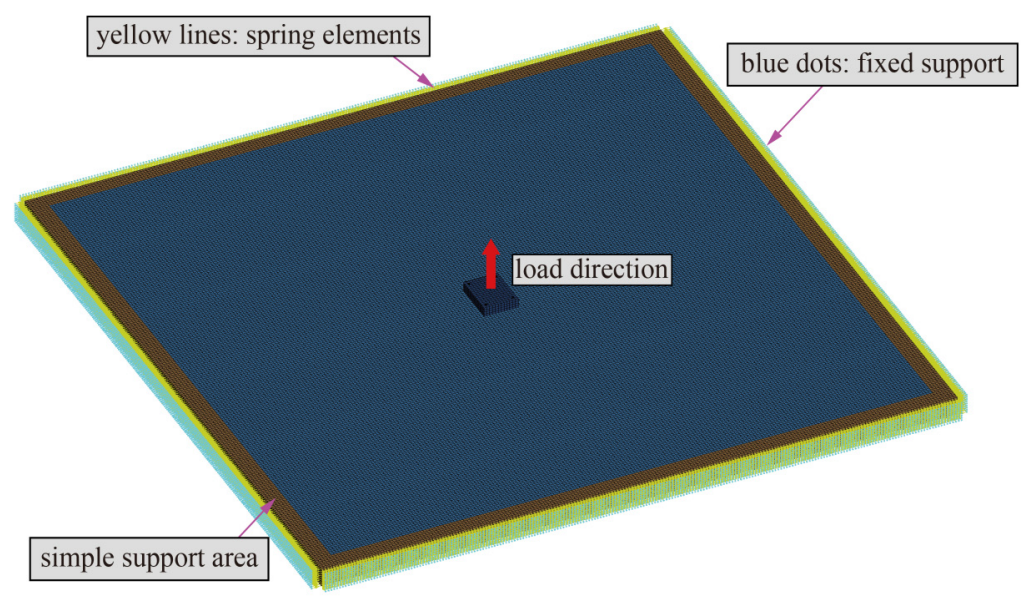

Fig. 10 The J1 model.

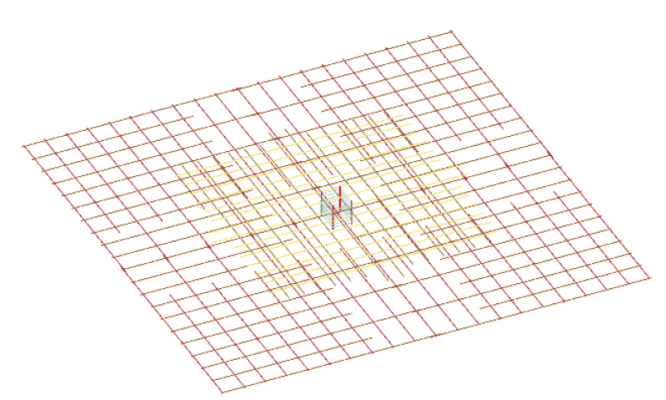

(a)

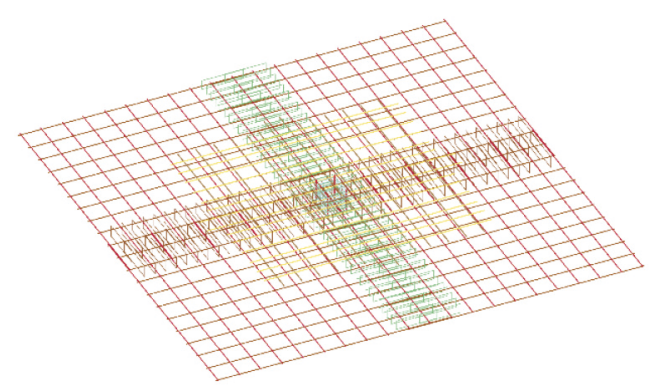

(b)

Fig. 11 Reinforcement layouts in the (a) J1 and (b) J2 models. 


\subsubsection{Bond-slip relationship}

Since a larger number of rebars in the slab bottom are connected by overlapped splices, bond-slip may occur between the overlapping rebars and between the concrete and reinforcement. The bond-slip effects are considered through the keyword *CONSTRAINED_BEAM_IN SOLID. The parameter set of "splitting, unconfined, all other bond condition" from the FIB Model Code [39] is chosen for both $\mathrm{J} 1$ and $\mathrm{J} 2$ models.

\subsection{Numerical results}

Figure 12 shows that the load-displacement curves of the $\mathrm{J} 1$ and J2 models. The punching shear capacity is increased by $6 \%$ due to the stricter requirement of the Chinese code [8]. After punching shear failure, the continuous integrity reinforcement confined by the embedded beams significantly increases the resistance in the post-punching stage under large deformations (by more than double).

The post-punching failure modes of the $\mathrm{J} 1$ and $\mathrm{J} 2$ models are presented in Fig. 13. By comparing the crack patterns in the vicinity of the column stub (see Figs. 13(a) and 13(c)), it can be found that crack distributions are more uniform in the $\mathrm{J} 2$ model; in addition, cracks in the $\mathrm{J} 2$ model are concentrated in closer proximity to the column, being much less spread than those in the J1 model. This is because more non-through-column reinforcement within the embedded beams can participate in resisting the applied load. This can also be clearly seen by comparing the reinforcement deformations in

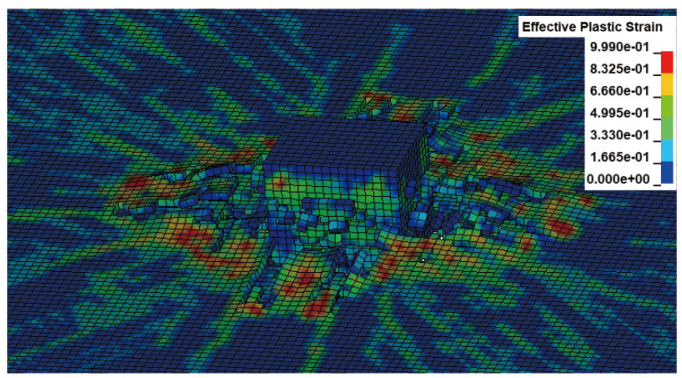

(a)

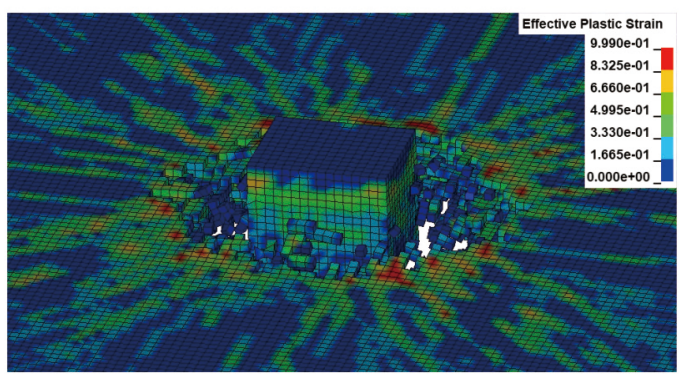

(c)
Figs. 13(b) and 13(d). Since the integrity of the J2 model is improved as a result of utilizing continuous integrity reinforcement and embedded beams, the flexural reinforcements are still able to work together with the concrete within the critical punching zone. Furthermore, the addition of the continuous through-column reinforcement and embedded beams in $\mathrm{J} 2$ enable greater load capacities in the post-punching suspension stage, at which its post-failure resistance increases by approximately $97 \%$, compared to that of $\mathrm{J} 1$.

It can be concluded that the collapsed building is prone to progressive collapse due to the weak construction detailing of the slab-column joints, thereby leading to very limited post-punching resistant capacities of the joints under large deformations. This, in turn, weakens the load redistribution capability of the overall structure.

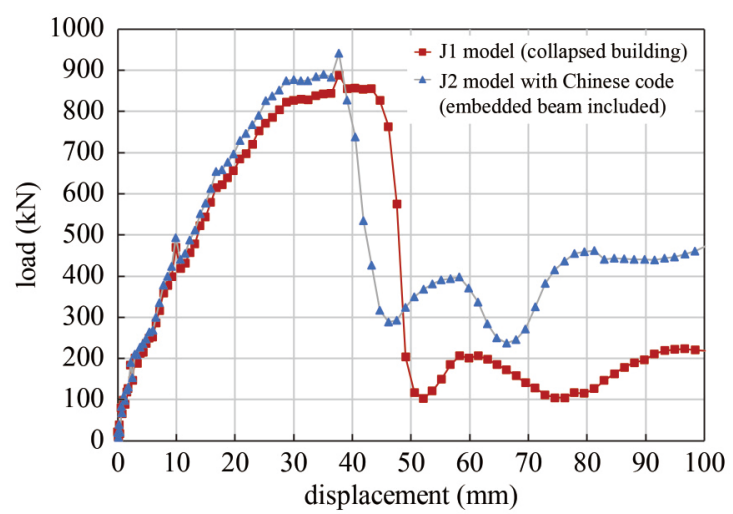

Fig. 12 Comparison of load-displacement curves between the $\mathrm{J} 1$ and $\mathrm{J} 2$ models.

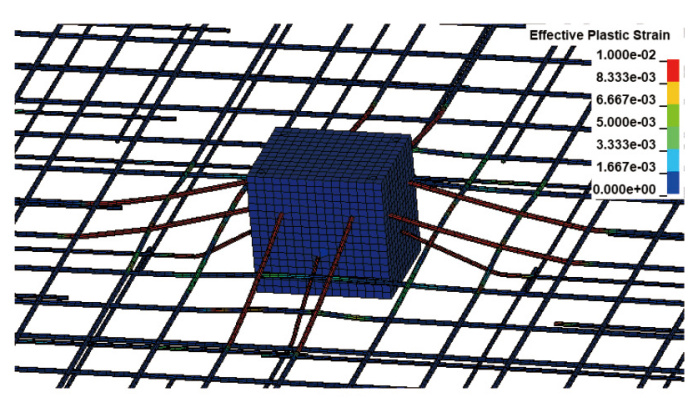

(b)

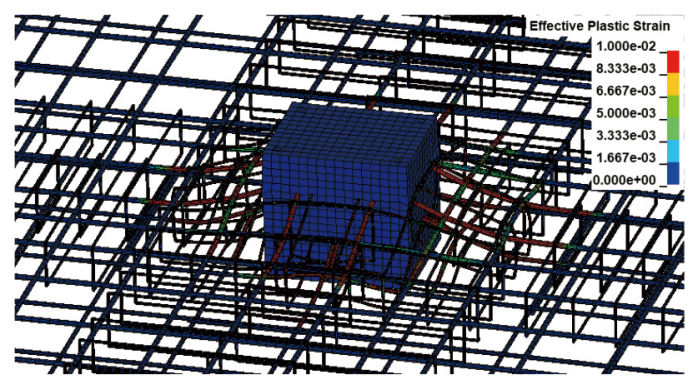

(d)

Fig. 13 Comparison of failure modes of $\mathrm{J} 1$ and $\mathrm{J} 2$ models after punching shear failure. (a) Concrete failure mode in $\mathrm{J} 1$ model; (b) reinforcement deformation in $\mathrm{J} 1$ model; (c) concrete failure mode in $\mathrm{J} 2$ model; (d) reinforcement deformation in J2 model. 


\section{Collapse simulation of the building}

A high-fidelity reconstruction of the collapse scenario is helpful for the public to have a greater level of understanding of the collapse accident. Consequently, based on the analysis described above, this section presents a high-fidelity simulation of the building collapse accident. Zheng et al. [36] proposed a hybrid framework combining finite element analysis and physics engine application to perform accurate and high-fidelity collapse simulation. Therefore, based on the study of Zheng et al. [36], this work adopts the following procedure to reconstruct the collapse scenario.

The simulation is implemented with the following three primary steps.

1) Geometric model establishment and conversion. First, the finite element software MSC.Marc is used to establish the structural model based on the design drawings. Subsequently, the computer code Fiber2RBD developed by Zheng et al. [36] is adopted to convert the finite element model to the geometric model in the physics engine.

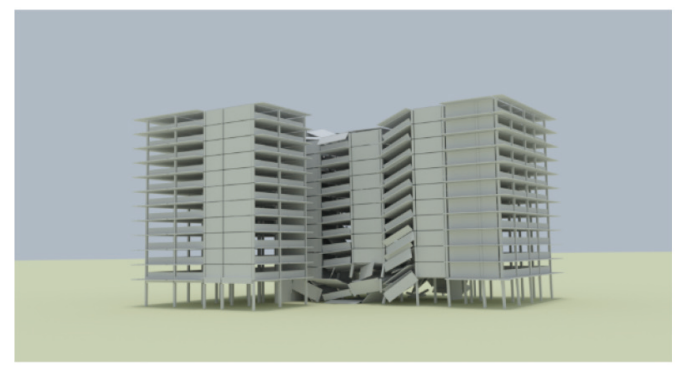

(a)

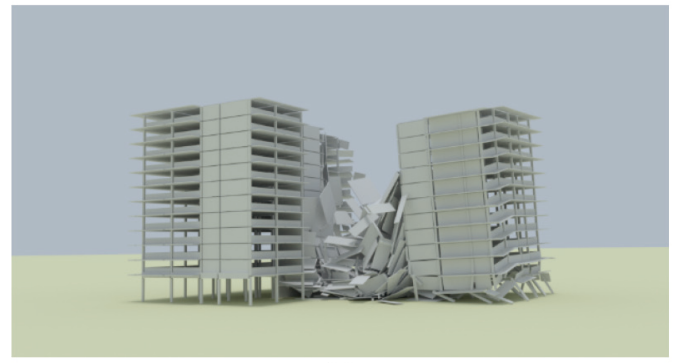

(c)

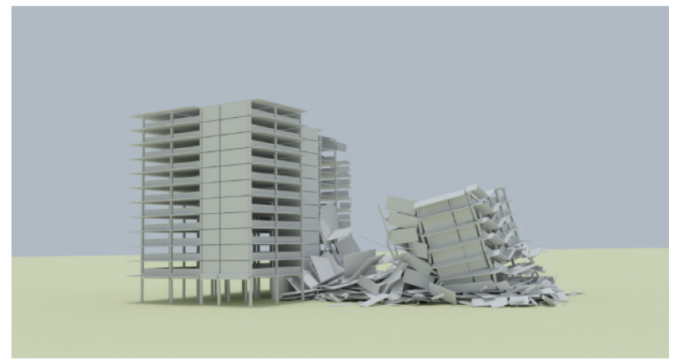

(e)
2) Physics engine model establishment. Based on the geometric model, the corresponding physics engine model is built up for computation, using the preprocess tool and constraint establishment method proposed by Oliver and Kostack [34].

3) Introducing initial damage. As of July 4nd, 2021, the definitive cause of the collapse is still unknown. Based on the news reported to date and the structural analysis presented in Sections 2 and 3, eight columns in the middle zone of the building (i.e., columns I-2, I-4, I-8, I$10, \mathrm{~K}-2, \mathrm{~K}-4, \mathrm{~K}-8$, and $\mathrm{K}-10$ in Fig. 2, enveloped by the blue-colored square) on the lobby level are removed to induce initial damage. Subsequently, the building model starts to collapse under the gravity load.

The simulated collapse process of the building is shown in Fig. 14, in which the left sub-figures are the simulated results, and the right ones are stills from the videos taken from the building site. The simulated collapse initiates from the column removal zone and propagates to the east (right) side due to the collision of the falling components. The simulated debris distribution and the actual collapse wreckage are compared in Fig. 15 with a very good

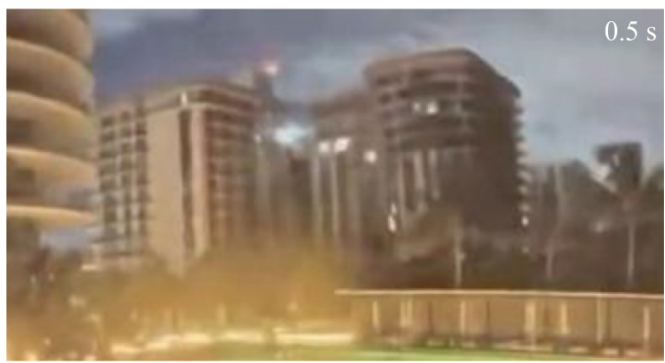

(b)

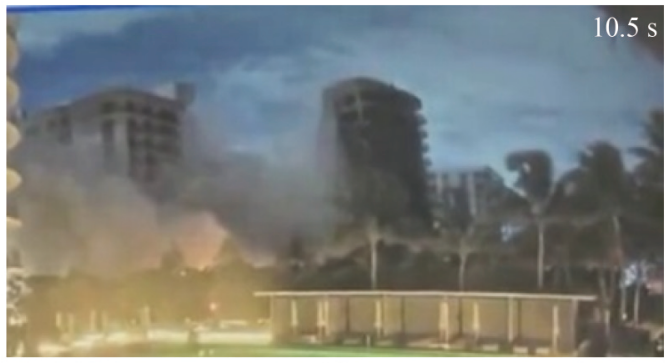

(d)

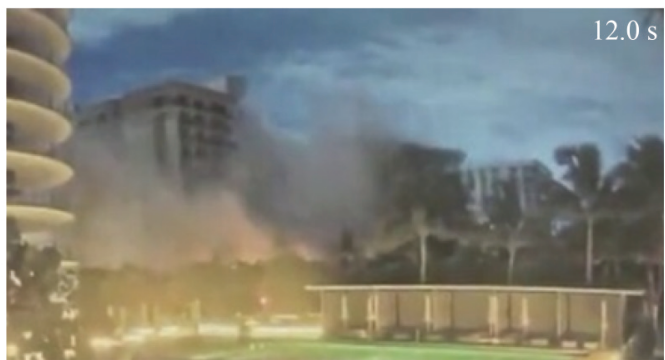

(f)

Fig. 14 Comparison between simulated and actual collapse processes (photos via Andy Slater). (a) Simulated collapse process 1; (b) actual collapse process 1; (c) simulated collapse process 2; (d) actual collapse process 2; (e) simulated collapse process 3; (f) actual collapse process 3. 


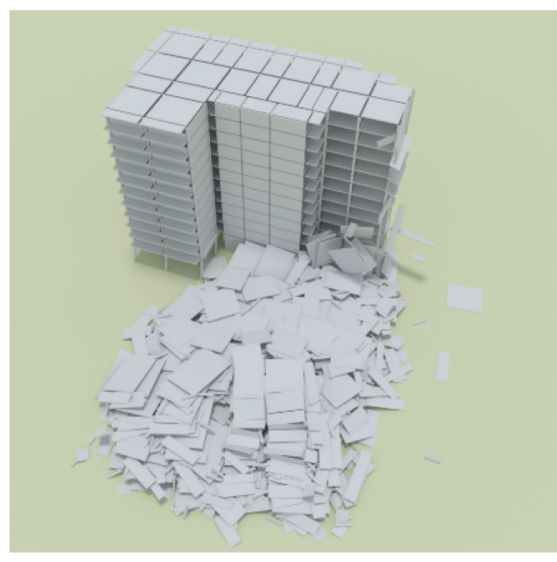

(a)

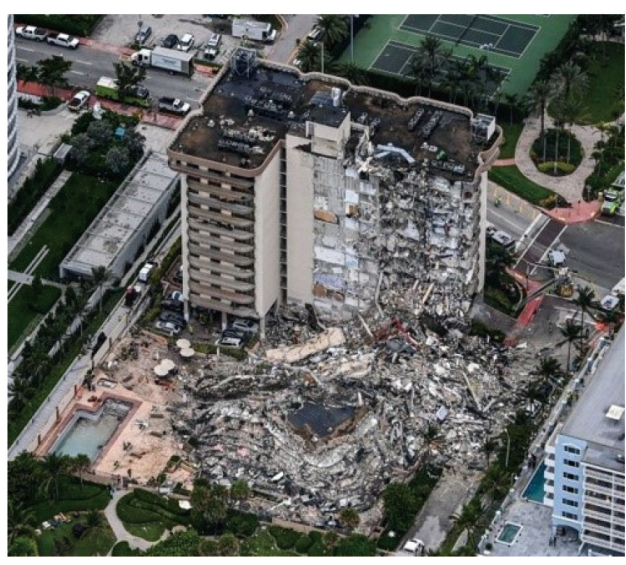

(b)

Fig. 15 Comparison between simulated and actual collapse wreckages (photo via Agence France-Presse). (a) Simulated collapse wreckage; (b) actual collapse wreckage.

agreement. It should be noted that the structural elements in the physics engine model are rigid bodies. The deformation and failure of the structural components are considered through the constraint definition between the rigid bodies. To perform this preliminary analysis in a timely manner with available computational resources, a relatively coarse meshing strategy is adopted, resulting in large intact panels in the simulation scenarios in Figs. 14 and 15.

\section{Conclusions}

In this work, the overall performance and key components of the collapsed flat plate building in Miami are quantitatively analyzed based on current Chinese and American building design codes. The punching shear behavior and post-punching failure mechanism under large deformations of a typical slab-column joint are also studied using the FE method. In addition, the collapse process is simulated and visualized using a physics engine. The outcome of the work leads to the following major conclusions.

1) The punching shear strengths of the key joints and the axial compressive strengths of the columns of the collapsed structure were low and fundamentally unable to meet the requirements of current Chinese design codes. A gravity column-shear wall system was adopted by the collapsed structure, and the number of shear walls was insufficient. The ratios of the shear walls built along the $X$ and $Y$ directions differed a lot. These features lowered the integrity and robustness of the building.

2) The FE analysis of the key slab-column joint discovers that the joint had limited strength at the large deformation stage due to poor reinforcement detailing. The overall structure lacked the ability to redistribute the internal forces, hence was likely to collapse progressively.
3) The visualized collapse simulation demonstrates that after the collapse of the middle part of the structure, the shear walls on the east side were not strong enough to prevent collapse propagation. The shear walls on the west side, on the other hand, were much stronger and thus did not experience progressive collapse.

4) In summary, the collapsed structure had a low level of safety margin, robustness, and resistance to progressive collapse, which in general can inevitably lead to serious consequences if local damage occurs due to unexpected and unforeseeable reasons.

In addition, the authors would like to reiterate that the analyses and conclusions of this work are based on the available information with certain assumptions and simplifications. Therefore, the study outcomes are not anticipated to be directly used for forensic analysis or other technical purposes.

Acknowledgements The authors are grateful for the financial support received from The National Key R\&D Program (No. 2019YFE0112800), the National Natural Science Foundation of China (Grant No. 51778341), and the Australian Research Council through an ARC Discovery Project (No. DP150100606).

Open Access This article is licensed under a Creative Commons Attribution 4.0 International License (https://creativecommons.org/licenses/ by/4.0/), which permits use, sharing, adaptation, distribution and reproduction in any medium or format, as long as you give appropriate credit to the original author(s) and the source, provide a link to the Creative Commons licence, and indicate if changes were made. The images or other third party material in this article are included in the article's Creative Commons licence, unless indicated otherwise in a credit line to the material. If material is not included in the article's Creative Commons licence and your intended use is not permitted by statutory regulation or exceeds the permitted use, you will need to obtain permission directly from the copyright holder. To view a copy of this licence, visit http:// creativecommons.org/licenses/by/4.0/. 


\section{References}

1. Wikipedia. Surfside Condominium Collapse. 2021

2. Ellingwood B R. Mitigating risk from abnormal loads and progressive collapse. Journal of Performance of Constructed Facilities, 2006, 20(4): 315-323

3. King S, Delatte N J. Collapse of 2000 Commonwealth Avenue: Punching shear case study. Journal of Performance of Constructed Facilities, 2004, 18(1): 54-61

4. Gardner N J, Huh J, Chung L. Lessons from the Sampoong department store collapse. Cement and Concrete Composites, 2002, 24(6): 523-529

5. Muttoni A, Ruiz M F, Fürst A, Guandalini S, Hunkeler F, Moser K, Seiler H. Structural Safety of Parking Garages. Documentation D 0226 Sia. Zürich: Swiss Society of Engineers and Architects, 2008

6. Swaine J, Shammas B, Lee J S, Mirza A, Brown E, Brittain A. Video, Images and Interviews Deepen Questions about Role of Pool Deck in Condo Collapse. 2021

7. ACI-318. Building Code Requirements for Structural Concrete. Farmington Hills: American Concrete Institute, 2019

8. GB 50010. Code for Design of Concrete Structure. Beijing: China Architecture \& Building Press, 2010

9. Xue H Z, Gilbert B P, Guan H, Lu X Z, Li Y, Ma F, Tian Y. Load transfer and collapse resistance of RC flat plates under interior column removal scenario. Journal of Structural Engineering, 2018, 144(7): 04018087

10. Xue H Z, Guan H, Gilbert B P, Lu X Z, Li Y. Comparative and parametric studies on behavior of RC-flat plates subjected to interior-column loss. Journal of Structural Engineering, 2020, 146(9): 04020183

11. Xue H Z, Guan H, Gilbert B P, Lu X Z, Li Y. Simulation of punching and post-punching shear behaviours of RC slab-column connections. Magazine of Concrete Research, 2021: 1-16

12. Ma F H, Gilbert B P, Guan H, Xue H Z, Lu X Z, Li Y. Experimental study on the progressive collapse behaviour of RC flat plate substructures subjected to corner column removal scenarios. Engineering Structures, 2019, 180: 728-741

13. Ma F H, Gilbert B P, Guan H, Lu X Z, Li Y. Experimental study on the progressive collapse behaviour of RC flat plate substructures subjected to edge-column and edge-interior-column removal scenarios. Engineering Structures, 2020, 209: 110299

14. Diao M Z, Li Y, Guan H, Lu X Z, Xue H Z, Hao Z. Post-punching mechanisms of slab-column joints under upward and downward punching actions. Magazine of Concrete Research, 2021, 73(6): 302-314

15. Yang Y Z, Li Y, Guan H, Diao M, Lu X Z. Enhancing postpunching performance of flat plate-column joints by different reinforcement configurations. Journal of Building Engineering, 2021, 43: 102855

16. Diao M Z. Punching and post-punching shear behaviour of interior RC slab-column joints with in-plane constraints. Dissertation for the Doctoral Degree. Queensland: Griffith University, 2021

17. Gu X L, Wang X L, Yin X J, Lin F, Hou J. Collapse simulation of reinforced concrete moment frames considering impact actions among blocks. Engineering Structures, 2014, 65: 30-41

18. Lu Z, He X D, Zhou Y. Discrete element method-based collapse simulation, validation and application to frame structures. Structure and Infrastructure Engineering, 2018, 14(5): 538-549

19. Salem H M, El-Fouly A K, Tagel-Din H S. Toward an economic design of reinforced concrete structures against progressive collapse. Engineering Structures, 2011, 33(12): 3341-3350

20. Grunwald C, Khalil A A, Schaufelberger B, Ricciardi E M, Pellecchia C, De Iuliis E, Riedel W. Reliability of collapse simulation-Comparing finite and applied element method at different levels. Engineering Structures, 2018, 176: 265-278

21. Li Y, Lu X, Guan H, Ye L. Progressive collapse resistance demand of reinforced concrete frames under catenary mechanism. ACI Structural Journal, 2014, 111(5): 1225-1234

22. Lu X Z, Lin K Q, Li Y, Guan H, Ren P Q, Zhou Y. Experimental investigation of $\mathrm{RC}$ beam-slab substructures against progressive collapse subject to an edge-column-removal scenario. Engineering Structures, 2017, 149: 91-103

23. Yang T, Han Z Q, Deng N C, Chen W. Collapse responses of concrete frames reinforced with BFRP bars in middle column removal scenario. Applied Sciences, 2019, 9(20): 4436

24. Chen X X, Xie W, Xiao Y F, Chen Y, Li X. Progressive collapse analysis of SRC frame-RC core tube hybrid structure. Applied Sciences, 2018, 8(11): 2316

25. Feng D C, Kolay C, Ricles J M, Li J. Collapse simulation of reinforced concrete frame structures. Structural Design of Tall and Special Buildings, 2016, 25(12): 578-601

26. Lu X, Lu X Z, Zhang W K, Ye L P. Collapse simulation of a super high-rise building subjected to extremely strong earthquakes. Science China. Technological Sciences, 2011, 54(10): 2549-2560

27. Lu X Z, Lu X, Guan H, Zhang W, Ye L P. Earthquake-induced collapse simulation of a super-tall mega-braced frame-core tube building. Journal of Constructional Steel Research, 2013, 82: 59-71

28. Lu X Z, Tian Y, Cen S, Guan H, Xie L L, Wang L S. A highperformance quadrilateral flat shell element for seismic collapse simulation of tall buildings and its implementation in OpenSees. Journal of Earthquake Engineering, 2018, 22(9): 1662-1682

29. Hartmann D, Breidt M, Nguyen V, Stangenberg F, Höhler S, Schweizerhof K, Mattern S, Blankenhorn G, Möller B, Liebscher M. Structural collapse simulation under consideration of uncertainty-Fundamental concept and results. Computers \& Structures, 2008, 86(21-22): 2064-2078

30. Millington I. Game Physics Engine Development. Boca Raton: CRC Press, 2007

31. Xu Z, Lu X Z, Guan H, Ren A. Physics engine-driven visualization of deactivated elements and its application in bridge collapse simulation. Automation in Construction, 2013, 35: 471-481

32. Zhou B J, Jia Q L, Chen Z J. The research and development of the erthquake ruins computer aided design system for rescue training. In: 2017 4th International Conference on Information Science and Control Engineering (ICISCE). Changsha: IEEE, 2017: 1303-1307

33. Xu Z, Lu X Z, Guan H, Han B, Ren A. Seismic damage simulation in urban areas based on a high-fidelity structural model and a physics engine. Natural Hazards, 2014, 71(3): 1679-1693

34. Oliver W, Kostack K. Final Release of the Blender and Bullet 
Physics Engine Based on Fast on-site Assessment Tool. 2017

35. Kostack Studio. Christchurch Earthquake Simulation \& Pyne Gould Building Collapse. 2016

36. Zheng Z, Tian Y, Yang Z B, Lu X Z. Hybrid framework for simulating building collapse and ruin scenarios using finite element method and physics engine. Applied Sciences, 2020, 10(12): 4408
37. Town of Surfside. Champlain Towers Public Records Documents. 2021

38. LSTC. LS-DYNA Keyword User's Manual. Livermore: Livermore Software Technology Corporation, 2015

39. FIB. Model Code for Concrete Structures 2010. Berlin: International Federation for Structural Concrete, 2013 